\title{
EXPLORING THE LINK BETWEEN BMI, PERCEIVED NEIGHBOURHOOD ENVIRONMENT AND HEALTH BEHAVIOURS IN MALAYSIA
}

\author{
M. RAFEE MAJID ${ }^{*}$, NOOR HASHIMAH HASHIM LIM $^{2}$, MUSARRAT ZAMAN ${ }^{3}$ AND \\ NORADILA RUSLIK ${ }^{1}$ \\ ${ }^{1}$ Faculty of Built Environment and Surveying, Universiti Teknologi Malaysia, UTM Skudai, 81310 Johor, Malaysia. \\ ${ }^{2}$ Department of Urban and Regional Planning, Centre for Sustainable Urban Planning and Real Estate (SUPRE), Faculty of \\ Built Environment, Universiti Malaya, Kuala Lumpur, Malaysia. ${ }^{3}$ Department of Disaster and Human Security Management, \\ Bangladesh University of Professionals (BUP), Dhaka, Bangladesh.
}

*Corresponding author: rafee@utm.my

Submitted final draft: 8 December 2020

Accepted: 24 December 2020

http://doi.org/10.46754/jssm.2021.10.015

\begin{abstract}
Obesity in Malaysia has become increasingly worrying. Besides health behaviours, perceived food and built environments have also been identified as influential factors on obesity. As such, this study aims to explain the obesity phenomenon through perceived environmental factors, health behaviours and the Body Mass Index (BMI). A conceptual model that reflects the interactions between Perceived Neighbourhood Food Environment (PNFE), Perceived Neighbourhood Built Environment (PNBE), Diet Quality (DQ), Physical Activity (PA) and BMI was developed. Adults $(n=256)$ were approached to complete the questionnaires used in this study. Exploratory and Confirmatory Factor Analyses were used to validate the constructs and produce the measurement model, while Structural Equation Modelling was used to compute the causal model. The proposed perceived neighbourhood environment, health behaviours and BMI causal model was a good fit. PNFE $(\beta=.192, \mathrm{p}=.032), \mathrm{DQ}(\beta=-.194, \mathrm{p}=.004)$ and PA $(\beta=-.189, \mathrm{p}=.010)$ were found to have significant direct effects on BMI, but not PNBE $(\beta=-.117, p=.143)$. This result also indicates that PNFE partially mediates the relationship between DQ and BMI, while PNBE does not mediate the relationship between PNBE and BMI. This suggests that the food environment is a highly significant predictor of BMI and should be explored more in future studies. The model illustrates the implications that urban planning has on health behaviours and health outcomes.
\end{abstract}

Keywords: Built environment, public health, obesity.

\section{Introduction}

The severity of the obesity issue is widely recognised as it does not only mean that a person is unable to function properly to carry out daily activities, it also indicates that the person is exposed to higher risks of developing chronic diseases as well. According to the National Health and Morbidity Survey (NHMS), evidence has shown that the percentage of overweight and obese Malaysian adults has almost doubled in the last 20 years between 1996 and 2016 . Obesity is said to be the result of interconnected determinants between the behavioural and environmental factors. Individual level factors alone are unable to fully explain the rise in the prevalence of obesity (Townshend \& Lake, 2017). Hence, it is recommended to also include community level factors in understanding health behaviours and health outcomes.

The composition of a neighbourhood-built environment more often has induced implicit influence on inhabitants' health, which can be explained through their behaviours of food consumption (Glanz et al., 2005) and physical activity (Sallis, 2009). In conjunction to that, the Malaysian National Strategic Plan for Non-Communicable Diseases (NSP-NCD, 2010) highlighted that the issue is believed to have stemmed from disjointed inter-sectoral collaborations, particularly between health professionals and urban planners, as well as a lack of strategic policies and regulatory interventions in creating a health-promoting built environment in Malaysia. 
There has been a considerably good number of studies that establish the relationship between the physical space of an environment and health outcomes within the context of a community (Glanz et al., 2005). The role of built environment as more than just a location has been heavily studied by health geographers (Kearns \& Moon, 2002), wherein the relationship between the environment and human health emerged. It was not until much later that literature on food environment started to appear. Hence, it was not surprising to seldom find the inclusion of both environmental aspects, i.e. the food environment and the built environment, concurrently in establishing a link to health behaviours and BMI.

Health-based non-clinical studies that were carried out in Malaysia can be found using the following predictors or factors, including demography (Hamid Jan et al., 2011; Wan Nazaimoon et al., 2011; Asma' et al., 2011; Cheong et al., 2013), socio-economic status (Norhasmah et al., 2010), food and diet (Ooi et al., 2015; Nurliyana et al., 2015; Fokeena et al., 2016), knowledge (Poh et al., 2012), psychosocial aspects (Lee et al., 2012; Zalina et al., 2012; Suzana et al., 2013; Rezali et al., 2015) and physical activity level (Zalina et al., 2012), with only one study using the factor of built environment (Hayati Adilin et al., 2015).

The above demonstrates the limited studies done in Malaysia regarding the influence of neighbourhood-level food environment and built environment on a person's diet quality and level of physical activity, and whether these factors affect a person's BMI. The Epidemiology and Disease Control Division of the Ministry of Health Malaysia released a statement in 2017, stating that researchers and intervention programmes established in Malaysia oftentimes face the problems of a lack of inter-sectoral efforts and negligence of contextual facets. This problem is apparent as out of all related past research done in Malaysia, there are limited studies done on predicting BMI and other health behaviours through neighbourhood level attributes, such as the physical environment pertaining to the issue.
As urban planning is able to encourage location decisions and designs of physical spaces (Dannenberg et al., 2003), it is able to encourage the formation of a balanced distribution of food variety and access to recreational facilities (Waxman, 2004). A consistent trend of significant relationships was found across literature review between Perceived Neighbourhood Built Environment (PNBE), physical activity (PA) and BMI. Most are highly suggestive that a healthy BMI is present among people who are physically more active and had better environmental perceptions (Duncan et al., 2012). Those environmental attributes include feeling that the walking/cycling routes are safe, having close proximity to local destinations regardless of geographical locations (Bourdeaudhuij et al., 2015), and having a better perception towards neighbourhood crime safety (Wiley et al., 2013). Being more satisfied with one's neighbourhood condition also contributes to having lower obesity rates (Webb et al., 2020).

All these environmental effects on obesity, according to Putrik et al. (2015), were found to be more consistent and stronger among older residents. Furthermore, a longitudinal study by Gutierrez et al. (2017) found that favourable changes in neighbourhood physical environments are related to BMI reductions in obese persons within the period of just one year. This is in tandem with the study by Claudel et al. (2019), which reported that regardless of race and socio-economic status, having good overall perceptions towards the built environment will induce a person to be more physically active.

As for the Perceived Neighbourhood Food Environment (PNFE), diet quality (DQ) and BMI, most studies concurred that an unhealthy BMI is present among people who have poor diet quality (Mesas et al., 2012) and perceived they had unfavourable food environment (Casey et al., 2008), e.g. high presence of buffets, cafeterias, and fast-food restaurants. This relationship is more apparent among people of low socio-economic status (Kell et al., 2015) and this causes "deprivation amplification", which increases individual risk factors for obesity. 
Considering the current needs and issues of the nation within the scope of the obesity phenomenon, it is thought that aspects of urban and regional planning through the perspective of environmental attributes is worth exploring and may be able to contribute in terms of gaining a better understanding of the epidemic. BMI is found to be a useful population-level measure of overweightness and obesity (Ranasinghe, et al., 2013). As such, BMI is deemed as a valid indicator to be used as the outcome variable of this study. Romieu et al. (2017) stressed that weight status is the direct effect of energy balance, i.e. energy intake and energy expenditure of a person. Romieu et al. (2017) continued to state that in the case of a person being overweight or obese, it is most likely that they have an imbalanced energy intake (poor diet quality) and energy expenditure (low physical activity).

Thus, this study hypothesised that diet quality and physical activity have direct effects on BMI, and they are categorised as the health behaviour predictors of the study. Evidence on diet quality (DQ) was obtained utilising the Diet Quality Index-Food Frequency Questionnaire (DQI-FFQ), while the evidence for physical activity (PA) was extracted utilising the Global Physical Activity Questionnaire (GPAQ) as recommended by the WHO. Details are discussed in the coming sections.

Also, supported by the Ecological System Theory forwarded by Bronfenbrenner (1992), who suggested that the behavioural development of a person is largely affected by the interaction with their surrounding environments, this study hypothesised that the environment, represented by Perceived Neighbourhood Food Environment (PNFE) and Perceived Neighbourhood Built Environment (PNBE), has direct effects on BMI. Moreover, it is also hypothesised that there is a correlation between PNFE and PNBE (Raja et al., 2010); PNFE and DQ (Green \& Glanz, 2015); as well as PNBE and PA (Sallis et al., 2012).

This present study was conducted based on respondents' self-reported perceptions at a neighbourhood level. The term "neighbourhood" in this study is adapted from Raja et al. (2010) as the standardised area traversable within 10 minutes of walking or 5 minutes of driving from the respondent's house. Ten minutes of walking or 5 minutes of driving are assumed to be the average distance one is willing to travel for food or the active mobility within their neighbourhood.

It is noted that self-reported perception of the food environment and built environment is found to be as significant as objectively measured food environment (Green \& Glanz, 2015). It is evident that this research area has been extensively studied in other countries with minor inconsistent results, whereby findings have shown that the perception-based nutrition environment (Glanz et al., 2016), as well as perception-based built environment (Hanibuchi et al., 2015; Martin et al., 2011), are consistently associated with health behavioural outcomes. This angle of public health research is, however, rarely collectively studied in Malaysia.

\section{Materials and Methods}

A stratified random survey involving questionnaires on PNFE, PNBE, DQ, PA and BMI were carried out in November 2018 on 256 adults (older than 18 years old). The first stage of the sampling involved the stratification of all 281 neighbourhoods in the Johor Bahru district into "lower NSES (Neighbourhood Socioeconomic Status)" and "higher NSES" using the median housing price per square foot of RM342 issued by the Valuation and Property Services Department of Malaysia at the time of the split.

Next, all the neighbourhoods categorised under lower and higher NSES were given a consecutive number of 1 to $N$. Then, 21 and 23 numbers representing the neighbourhoods were randomly selected from each group of NSES, respectively, using a random number generator (software) before respondents were randomly selected in the same manner from the sampled neighbourhoods. In the end, a total of 176 randomly selected respondents from the lower NSES group and 80 respondents from 
the higher NSES group were administered the questionnaires with the aid of six trained enumerators.

\section{Outcome Variable}

Body Mass Index (BMI) was derived through self-reported height and weight by respondents, which was then calculated by dividing weight (kilograms) with squared height (metres). The BMI cut-off recommended by the Malaysian Dietary Guidelines 2010 (MDG 2010) was referred to for classifications. The recommended categories are underweight (less than $18.5 \mathrm{~kg} /$ $\mathrm{m}^{2}$ ); normal $\left(18 \cdot 5-24.9 \mathrm{~kg} / \mathrm{m}^{2}\right)$; overweight (25$\left.29.9 \mathrm{~kg} / \mathrm{m}^{2}\right)$; and, obese $\left(30 \mathrm{~kg} / \mathrm{m}^{2}\right.$ or higher $)$.

\section{Environmental Predictors}

The questionnaire on Perceived Neighbourhood Food Environment (PNFE) has a total of 22 items. Firstly, perceived food store type availability (PFSA) is adapted from Morland et al. (2006), Treuhaft and Karpyn (2010) and Ploeg (2010), which collects the food store density expressed in the number of food store types available within a stipulated radius. As this study seeks to collect self-reported perceptions, the question was rephrased by collecting perceived counts based on 5 food store types available within a 10 -minute walk or 5 -minute drive from the respondent's house. The food store types include supermarkets, grocery stores, non-fast-food restaurants, convenience stores and fast-food restaurants. Secondly, perceived geographical food accessibility (PGFA) was adapted from Gustafson et al. (2011), Bridle-Fitzpatrick (2015) and Caspi et al. (2012), whereby the food store type under "perceived distance of food stores from home" was extended to those 5 types of food stores mentioned above. Furthermore, the open-ended questions in the original versions were changed to close-ended questions with a 6-point Likert scale (1-5 min, 6-10 min, 11-20 min, 21-30 min, $>30$ mins or not sure).

Thirdly, perceived healthy food availability (PHFA) was adapted from the original Perceived Nutrition Environment Measures Survey
(NEMS-P) developed by Green \& Glanz (2015), which consists of 6 questions, with a 5-point Likert scale. This study maintained the nature of the questions, but reduced the scale to 4 points, ranging from strongly agree, somewhat agree, and somewhat disagree to strongly disagree. The scale was reduced to force respondents to form much-needed opinions and elicit specific responses for the study, rather than having them choosing the "neutral" middle category. The final variable under PNFE, perceived food affordability (PFA), was adapted from Blitstein et al. (2002) and Inglis et al. (2008). Although the original questions only gauged perceived affordability of fruit and vegetables, this study extended the questions to include more categories of healthy and unhealthy food, with a 4-point Likert scale. The categories added were fresh produce (tempe, tauhu, meat and seafood), low fat products (low fat milk and lean meats), sugar sweetened beverages, snacks (sweets, candies, chocolates, cookies and ice creams), and fast food.

The questionnaire on Perceived Neighbourhood Built Environment (PNBE), which has a total of 38 items, was adapted from the previously validated Neighbourhood Environment Walkability Scale (NEWS) questionnaire by Saelens et al. (2003), which intends to measure self-reported perceptions of the physical built environment related to physical activity. For perceived residential density (PRD), the study retained the nature of the questions but modified the housing type terms that were deemed more appropriate for Malaysian respondents. For example, the term "detached single-family residences" was changed to "bungalow, semi-detached and cluster housing", and "row houses of 1 to 3 storeys" was changed to " 1 - to 3 -storey terrace". During data processing for PRD, weightage based on residential density were assigned to all types of housing as required after adjustment of weightage to suit the Malaysian housing conditions. The Planning Standards and Guidelines Manual Johor, Malaysia (2013) guided the weightage assignment, whereby less weightage was assigned to low-density housing 
and higher weightage for high-density housing. As an example, the lowest-density housing with an average density of 8 units per acre, such as bungalows and semi-detached homes, were assigned a weight of 8 , equivalent to the value given in the United States for lowest-density housing, while high-density apartments and condominiums were assigned a weight of 70, the highest weightage in the NEWS questionnaire.

In order to produce a concise and short questionnaire, land-use activity groupings were created for the questions on perceived land use mix diversity (PLMD), whereby 6 groups, i.e. supermarkets, local neighbourhood stores, restaurants, services, specialty stores and public facilities, were created from the original 23 items. The study retained the original answering range of " 1 to 5 minutes", "6 to 10 minutes", "11 to 20 minutes", "21 to 30 minutes", "more than 30 minutes" and "not sure". The questions from here onwards were provided with a 4-point Likert scale answering range of "strongly agree", "somewhat agree", "somewhat disagree" and "strongly disagree". For perceived land-use mix accessibility (PLMA), the original 6 questions from the NEWS questionnaire were retained, whereby respondents were asked to rate their level of agreements while bearing in mind the perceived land uses within 10 minutes' walking distance from their residences.

For perceived walking and cycling facilities (PWCF), out of the 10 original questions, only 4 questions were adapted for this study based on Malaysia's geographical suitability, e.g. availability, maintenance, ease of access to and connections of walking and cycling facilities. Next, for perceived surrounding aesthetics (PSA), out of 8 questions, only 5 were retained, including the availability of interesting natural and man-made features to look at, street cleanliness, as well as tree shade. For perceived street connectivity (PSC), the original 5 questions in the NEWS questionnaire were retained in the study. Finally, for perceived safety from traffic and crime (PSTC), only 3 questions on traffic safety, e.g. traffic conditions, traffic speed and air pollution, as well as 3 questions on crime safety, e.g. lighting quality at night, pedestrian visibility and social interaction, were retained in the questionnaire for this study.

Although the structures of manifest and latent variables of the current study are based on numerous validated theories from previous studies, those research were done in foreign countries. As mentioned earlier, one of the obesity research gaps in Malaysia is the lack of studies done using a local data set to have a better reflection of the local situation. Hence, the current study decided to reconfirm and increase structure accuracy by conducting an EFA using a local data set. Secondly, the current study has done some modifications to the original NEWS and NEWS-CFA questionnaires, as such, conducting an EFA is treated as a cautionary step.

It is efficient to do so because it explores underlying theoretical factor structures by identifying and producing groups among variables with strong correlations in a data set. As EFA can be done only on non-nominal or non-continuous scaled items, single measured items in the study including perceived groceries availability, perceived non-fast food restaurant availability, perceived convenience store availability, perceived fast food restaurant availability, perceived groceries geographical access, perceived non-fast food restaurant geographical access, perceived convenience store geographical access, perceived fast food restaurant geographical access, perceived residential density and perceived land use mix diversity were excluded from this analysis.

Exploratory Factor Analysis (EFA) was conducted using Principal Component Analysis (PCA) and Promax as the factor extraction and rotation method. As demonstrated in Table 1, data adequacy was fulfilled, with the value of Kaiser-Meyer-Olkin (KMO) being 0.898, while the Bartlett's Test of Sphericity significance value of 0.000 indicated that the EFA output from this data set was meaningful with 7 factors extracted accounting for $68.225 \%$ of the total variance explained. Based on the communalities table, none of the items had communalities issue by having a value of less than 0.30 . 
All of the items were loaded under each respective factor as expected in the table. The output is said to have achieved validity through proving convergent validity by having factor loadings of greater than 0.40 under each item, as well as discriminant validity, whereby highly correlated items were seen to be significantly loaded under the same factor in the EFA pattern matrix as depicted in the same table. Moreover, as the items were loaded under the same factor as initially expected, the face validity was ascertained. Additionally, the internal reliability of the extracted factors showed that the output has achieved reliability by having Cronbach's alpha values of greater than 0.70 .

Table 1: Exploratory Factor Analysis on the items of the adapted questionnaire

\begin{tabular}{|c|c|c|c|c|}
\hline No. & Factor & Item/Variable & $\begin{array}{c}\text { Factor } \\
\text { Loading }\end{array}$ & $\begin{array}{l}\text { Cronbach's } \\
\text { Alpha Value }\end{array}$ \\
\hline 1 & $\begin{array}{l}\text { Perceived } \\
\text { healthy food } \\
\text { availability } \\
\text { (FHA) }\end{array}$ & $\begin{array}{l}\text { Fruits and vegetables access } \\
\text { Low-fat products selection } \\
\text { Low-fat products access } \\
\text { Fruits and vegetables selection } \\
\text { Low-fat product quality } \\
\text { Fresh produce quality }\end{array}$ & $\begin{array}{l}.859 \\
.841 \\
.839 \\
.833 \\
.822 \\
.804\end{array}$ & 0.938 \\
\hline 2 & $\begin{array}{l}\text { Perceived food } \\
\text { affordability } \\
(\mathrm{AFF})\end{array}$ & $\begin{array}{l}\text { Sugar sweetened beverages } \\
\text { Snacks and junk food } \\
\text { Fast food } \\
\text { Low-fat products } \\
\text { Fruits and vegetables } \\
\text { Fresh produce }\end{array}$ & $\begin{array}{l}.851 \\
.826 \\
.791 \\
.765 \\
.758 \\
.737 \\
\end{array}$ & 0.916 \\
\hline 3 & $\begin{array}{l}\text { Perceived land } \\
\text { use mix access } \\
\text { (BLMA) }\end{array}$ & $\begin{array}{l}\text { Local commercial stores } \\
\text { Many places within walking distance } \\
\text { Parking in shopping areas } \\
\text { Transit stop (bus, taxi) } \\
\text { Recreational parks } \\
\text { Diversity of shopping areas }\end{array}$ & $\begin{array}{l}.851 \\
.845 \\
.833 \\
.818 \\
.444 \\
.411\end{array}$ & 0.866 \\
\hline 4 & $\begin{array}{l}\text { Perceived } \\
\text { walking and } \\
\text { cycling facilities } \\
\text { (BWC) }\end{array}$ & $\begin{array}{l}\text { Availability of sidewalks } \\
\text { Well-maintained sidewalks } \\
\text { Connection of pedestrian trails } \\
\text { Availability of pedestrian trails }\end{array}$ & $\begin{array}{l}.821 \\
.788 \\
.563 \\
.537\end{array}$ & 0.783 \\
\hline 5 & $\begin{array}{l}\text { Perceived } \\
\text { surrounding } \\
\text { aesthetics } \\
\text { (BSA) }\end{array}$ & $\begin{array}{l}\text { Presence of shady trees } \\
\text { Presence of trees along the streets } \\
\text { Neighbourhood free from litter } \\
\text { Presence of natural attractive sights } \\
\text { Presence of attractive man-made structures }\end{array}$ & $\begin{array}{l}.764 \\
.728 \\
.682 \\
.665 \\
.561\end{array}$ & 0.842 \\
\hline 6 & $\begin{array}{l}\text { Perceived safety } \\
\text { from traffic and } \\
\text { crime } \\
\text { (BC) }\end{array}$ & $\begin{array}{l}\text { Visibility of pedestrians } \\
\text { Presence of exhaust fumes } \\
\text { Condition of street lighting at night } \\
\text { Communication with other people } \\
\text { Driver behaviour - speed limit } \\
\text { Traffic affecting difficulty to walk }\end{array}$ & $\begin{array}{l}.788 \\
.774 \\
.738 \\
.691 \\
.690 \\
.625\end{array}$ & 0.869 \\
\hline 7 & $\begin{array}{l}\text { Perceived street } \\
\text { connectivity } \\
(\mathrm{BSC})\end{array}$ & $\begin{array}{l}\text { Length between intersections } \\
\text { Connections of cul-de-sacs } \\
\text { Presence of cul-de-sac } \\
\text { Presence of four-way intersections } \\
\text { Presence of alternative routes }\end{array}$ & $\begin{array}{l}.785 \\
.771 \\
.745 \\
.698 \\
.663\end{array}$ & 0.874 \\
\hline
\end{tabular}




\section{Health Behaviour Predictors}

Diet Quality (DQ) was gauged by requesting information on food frequency intake and serving sizes for daily consumption according to food groups. The study utilised the Diet Quality Index- Food Frequency Questionnaire (DQI-FFQ), which was previously validated in Malaysia by Fokeena et al. (2016), to assess respondents' yearly average food intake. It is understood that the said index was developed based on the current nutrition information and dietary guideline recommended by the MDG 2010, as well as the Malaysia Food Pyramid (MFP). The index used a combination of indicators including food groups, serving size, and food frequency intake, which are then compared to the recommended intake of an individual to derive their diet quality. As dietary requirements vary from one individual to another based on the amount of energy exertion, the recommended intake of a person should be according to gender and physical activity level. The DQI-FFQ uses a 5-point scoring system, whereby the highest point of 5 is awarded to respondents who have adhered to their recommended intake based on their gender and physical activity levels, and the lowest point of 0 is given to respondents who did the opposite.

Physical Activity (PA) was derived through utilising the Global Physical Activity Questionnaire (GPAQ) as recommended by the WHO. It comprises 4 parts, and gauges respondents' physical activity on a weekly basis in terms of activities in workplace, travel to and from destinations, and leisure activities, as well as sedentary activities, excluding sleeping time. According to the Malaysian Dietary Guideline 2010, Key Message 3, Metabolic Equivalent Task (MET) is defined as the absolute amount of energy or resting rates of oxygen used during certain activities.

Supporting this statement, GPAQ Analysis Guidelines stated that MET is widely utilised to explain intensity of physical activities, where it is the working metabolic rate relative to resting metabolic rate of an individual. As such, 1 MET is assumed to be used by a resting or sedentary individual, 4 METs is assumed to be used by a moderately active individual, and 8 METs is assumed to be used by a vigorously active individual. As the GPAQ intends to measure an individual's physical activity on a weekly basis, the respondent's active day(s) per week and minutes per day is recorded and multiplied by the METs assigned. As such, 3 classifications were introduced, i.e. vigorously active (more than 3001 METs per week), moderately active (601 to 3000 METs per week) and sedentary (less than 600 METs per week).

\section{Confounding Variables}

Socio-demographic characteristics, including age, race, gender, highest education level and monthly household income, were derived from the respondents. Neighbourhood socioeconomic status (NSES) was derived by asking respondents to report the names of the street they are living in and their neighbourhood. This information was then checked for respective median property values based on the latest transactions as reported in the Valuation and Property Services Department of Malaysia.

\section{Statistical Analysis}

Data were recorded using the IBM Statistical Package for Social Sciences (SPSS) version 22.0, while CFA and SEM analyses were conducted using IBM SPSS AMOS (AMOS) version 23.0. With a priori sample size calculation (Wolf et al., 2013), by using the probability level of 0.05 , statistical power level of 0.8 , as well as an anticipated effect size of 0.3 , the recommended minimum sample size for this study was at least 212. Data assumptions, including missing cases, outliers, multicollinearity, normality, linearity and homoscedasticity were checked for the data set.

Pooled Confirmatory Factor Analysis (CFA) was conducted on the latent variables and the respective manifest variables simultaneously for perceived neighbourhood food environment, perceived neighbourhood built environment, diet quality and physical activity. After the measurement model's construct validity was verified, Structural Equation Modelling (SEM) 
was used to examine the extent to which the conceptual model of perceived neighbourhood environment, health behaviours and BMI is supported by the sample data collected.

As there are three main categories of fitness, including absolute fitness, incremental fitness and parsimonious fitness, Hair et al. (2010) suggested that studies should use at least one index from each fitness category. Hence, model fit indices referred to in this study are CMIN, relative CMIN (CMIN/df), comparative fit index (CFI), Tucker-Lewis Index (TLI) and root mean square error of approximation (RMSEA).

Values indicating a good model fit are CMIN/df of not more than 5 (Wheaton et al., 1977); CFI that is closer to 1 ( $\mathrm{Hu} \&$ Bentler, 1999); TLI that is closer to 1 (Tucker \& Lewis, 1973) and RMSEA of not more than 0.08 (Hu \& Bentler, 1999). Maximum Likelihood Estimator was used for both CFA and SEM, while a $95 \%$ confidence interval level was used to test construct significance. The standardised regression weights were recommended as a reference for predictor-outcome relationships across variables of differing units of analysis (Landis, 2005), such as that of this study.

\section{Results and Discussion}

\section{Socio-demographic Characteristics, NSES and BMI}

The study has a total of 256 respondents. The mean age of the respondents were 34 years old $(S D=12.6)$, most were male $(59 \%)$, of Malay ethnicity (50\%), and their highest education level was at the tertiary level $(50 \%)$, had a monthly household income of RM5001-RM7000 (30\%). Overall, there was more participation from respondents living in the lower NSES (69\%) than higher NSES (31\%). For diet quality, most respondents were at risk of poor diet quality (59\%). As for physical activity, the mean MET value per week of respondents was $1794(S D \pm$ 2115), which can be categorised as moderately active.

Table 2 shows the overall and the proportion of the sample distribution according to BMI.
Those who have normal BMI were of a younger age group of between 18 and 30 years old, female, of Chinese and Others ethnicity, had tertiary education as the highest education level with a monthly household income of more than RM10,001 and were from the higher NSES. As expected, most of them were at a lower risk of poor diet quality and were vigorously active. On the other hand, those who had a BMI of higher than 25 were middle-aged, between 31 to 50 years old, male, of Malay and Indian ethnicity, and their highest education level was at the primary school level, with a monthly household income of less than RM3,000. Most of the respondents from this cohort were at risk of poor diet quality and were physically inactive (sedentary).

\section{Latent Variables of PNFE, PNBE, DQ and PA}

The outcome of standardised regression weights and significance values of the measurement model from Pooled CFA for those significant paths are presented in Figure 1 and the measurement model achieved goodness-of-fit $(\mathrm{CMIN}=1677.45, \mathrm{df}=1101, \mathrm{CMIN} / \mathrm{df}=1.524$, $\mathrm{TLI}=.928, \mathrm{CFI}=.933, \mathrm{RMSEA}=.045)$.

For correlation analysis, both PNFE and PNBE were found to be influential towards a person's health behaviours, which then ultimately contributes to their BMI, and it is not surprising to find that PNFE and PNBE $(\beta=.425, p<.000)$ were significantly correlated with each other. Supporting the claims of previous studies, this study also found that the environmental factors correlate with health behaviours, specifically PNFE correlates with a person's DQ $(\beta=.297, \mathrm{p}<.000)$ (Rummo et al., 2015) and PNBE correlates with a person's PA $(\beta=.402, p=.005)$ (Yu et al., 2017). Also, an unexpected correlation was found between PNFE and PA $(\beta=.297, p<.000)$.

\section{Causal Model of Perceived Neighbourhood Environment, Health Behaviours and BMI}

The perceived neighbourhood environment, health behaviours and BMI causal model (Figure 2) was drawn using the imputed measurement 
model produced while inserting BMI as the dependent manifest variable, as well as other confounding independent manifest variables, i.e. sociodemographic characteristics and NSES. A non-linear nature was found for the factor of "race" ( $p=0.008)$; thus it was not included in the causal model. The model fitness was established $(\mathrm{CMIN}=2.920, \mathrm{df}=2, \mathrm{CMIN} / \mathrm{df}=1.460, \mathrm{TLI}=$ .983, CFI $=.997$, RMSEA=.042). At a 95\% confidence interval level, the significant direct effects were presented in bold lines, while the insignificant direct effects were presented in dotted lines.

Firstly, PNFE ( $\beta=.192, p=.003)$ was found to have a significant positive direct effect on BMI. This is apparent as most of the respondents who reported poor DQ had a higher BMI. As expected, both health behaviours, i.e. DQ ( $\beta=-$ $.194, \mathrm{p}=.004)$ and PA $(\beta=-.189, \mathrm{p}=.010)$, have significant negative direct effects on BMI as weight is essentially the outcome of energy intake and energy expenditure. Additionally, the result also showed that both health behaviours are significantly related to each respective environment; PA and PNBE $(\beta=.453, \mathrm{p}<.000)$, as well as DQ and PNFE $(\beta=.323, \mathrm{p}<.000)$.

As for confounding variables, the findings of this study add to the collection of previous studies, which reported that those with lower monthly household income $(\beta=-.171, \mathrm{p}=.006)$ and lower education level $(\beta=-.149, p=.016)$ had the higher BMI values. This is evident as most of the respondents who have higher BMI have finished only primary school and had a monthly household income of less than RM3,000. Other than that, gender $(\beta=-.145, p=.019)$ was found to be significantly related to BMI, but not age $(\beta=.115, p=.065)$ and NSES $(\beta=-.089, p=.153)$.

It should also be noted that as PNBE was insignificantly related to $\mathrm{BMI}$, the mediation effect of PNBE towards the relationship between $\mathrm{PA}$ and BMI was insignificant. On the other hand, as both PNFE and DQ have significant relationships with BMI, this denotes the presence of a partial mediation effect of PNFE towards the relationship between DQ and BMI.

In the present study, the obesity phenomenon, represented by BMI, was explored within the context of perceived neighbourhood environment and health behaviours. It is evident that the perceived neighbourhood food environment has a direct effect in influencing a person's BMI, but not perceived neighbourhood built environment. In tandem with the findings of Raja et al. (2010), this study also discovered that the food environment (PNFE) had a higher influence on BMI than the built environment (PNBE).

Table 2: Socio-demographic characteristics of the respondents $(n=256)$

\begin{tabular}{lccc}
\hline & \multicolumn{2}{c}{ Proportion Distribution (100\%) } \\
\hline Oender (\%) & Overall & Normal BMI (\%) & Overweight/Obese BMI (\%) \\
Male & 59 & 86 & 14 \\
Female & 41 & 90 & 10 \\
\hline Age (\%) & & & \\
$18-30$ years old & 40 & 92 & 8 \\
$31-50$ years old & 42 & 86 & 14 \\
$>51$ years old & 18 & 89 & 11 \\
\hline Race (\%) & & & 6 \\
Malay & 50 & 86 & 12 \\
Chinese & 32 & 94 & 0 \\
Indian & 16 & 88 & 14 \\
Others & 2 & 100 & \\
\hline
\end{tabular}




\begin{tabular}{lccc}
\hline Education (\%) & 19 & 73 & 27 \\
Primary & 31 & 81 & 19 \\
Secondary & 50 & 96 & 4 \\
Tertiary & & 60 & 40 \\
\hline Household Income (\%) & 10 & 81 & 19 \\
SRM3,000 & 21 & 87 & 13 \\
RM3,001-RM5,000 & 30 & 95 & 2 \\
RM5,001-RM7,000 & 21 & 98 & 15 \\
RM7,001-RM10,000 & 18 & 85 & 7 \\
$\geq$ RM10,001 & & 93 & \\
\hline Neighbourhood Socioeconomic & 69 & & 4 \\
Status (\%) & 31 & 96 & 14 \\
Lower & & 86 & 20 \\
Higher & 23 & 85 & 2 \\
\hline Leisure Time Physical Activity (\%) & 51 & 80 & \\
Vigorously active & 26 & 98 & \\
Moderately active & & & \\
Sedentary & 59 & 41 &
\end{tabular}

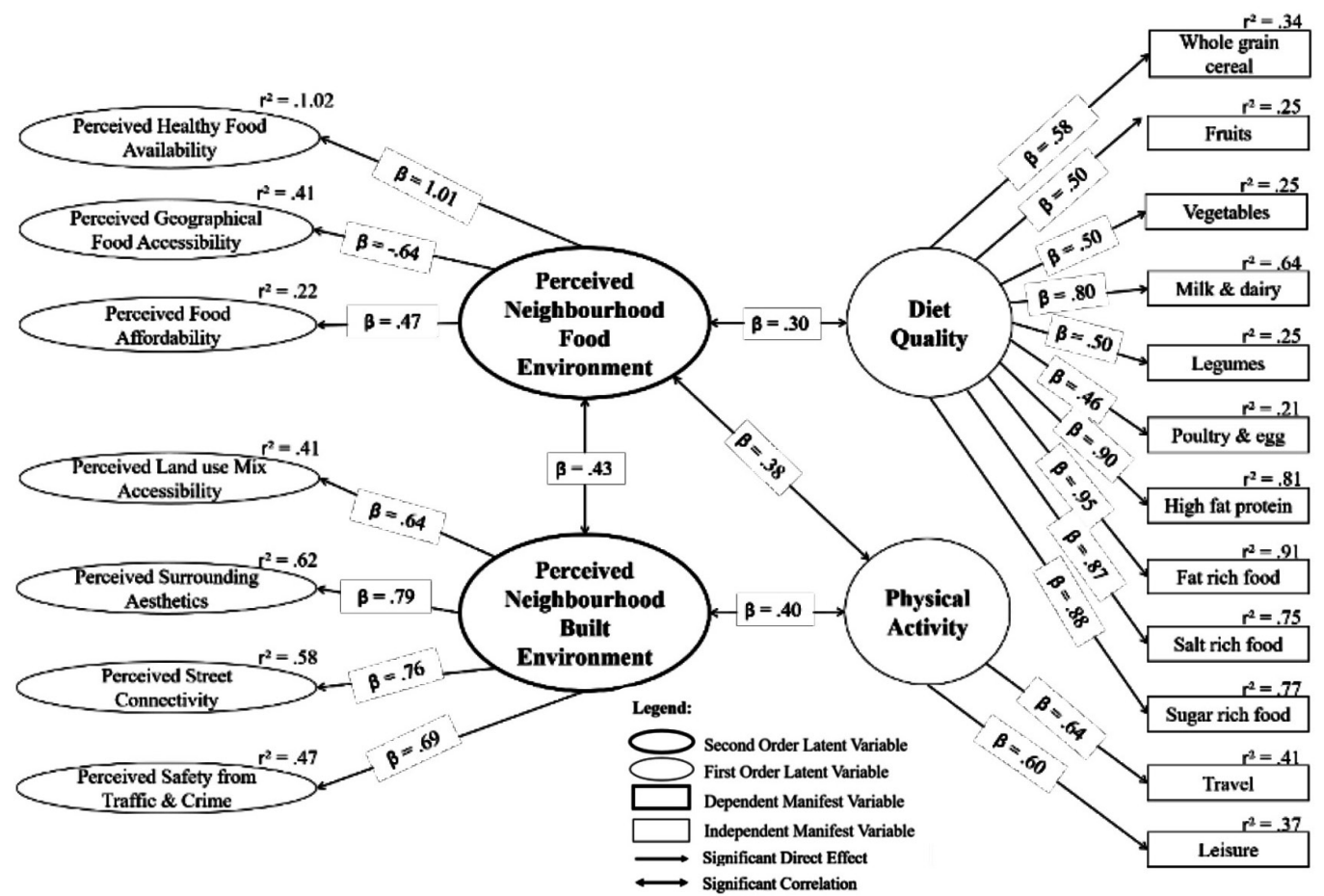

Path Coefficients: $\beta=$ Standardised Regression Weight, $\mathrm{r}^{2}=$ Squared Multiple Regression Model fit: $\mathrm{CMIN}=1677.45, \mathrm{df}=1101, \mathrm{CMIN} / \mathrm{df}=1.524, \mathrm{TLI}=.928, \mathrm{CFI}=.933, \mathrm{RMSEA}=.045$

Figure 1: Measurement model of perceived neighbourhood environment and health behaviours 


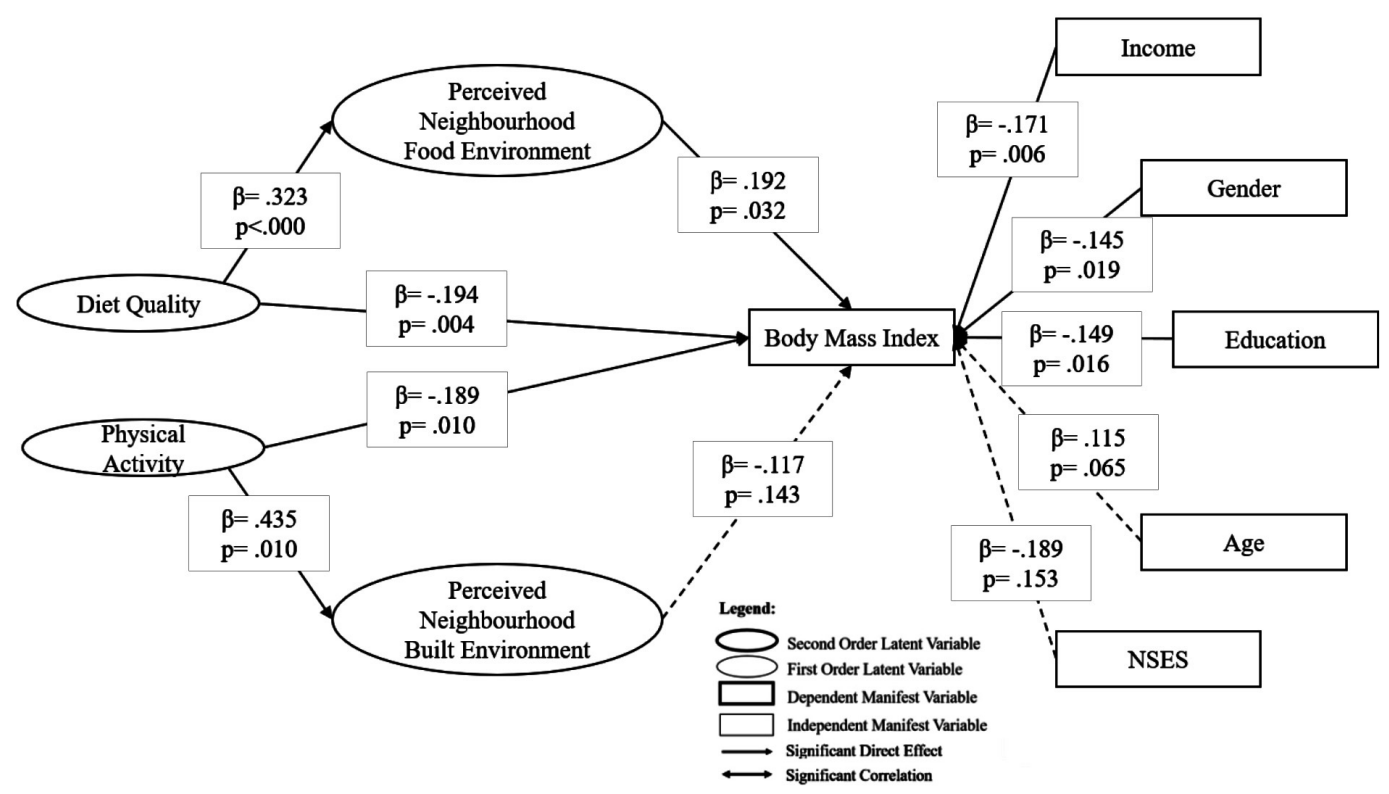

Path Coefficients: $\beta=$ Standardised Regression Weight,

Model fit: $\mathrm{CMIN}=2.920, \mathrm{df}=2, \mathrm{CMIN} / \mathrm{df}=1.460, \mathrm{TLI}=.983, \mathrm{CFI}=.997, \mathrm{RMSEA}=.042$

Figure 2: Causal model of perceived neighbourhood environment, health behaviours and BMI

The negative moderate effects that the environmental factors had on BMI means that the higher the scores (better) of PNFE and PNBE, the lower (normal BMI <25) the BMI of a respondent, and vice versa. This concurs with a myriad of previous studies, which had similar results, such as those done by Gibson (2011) and Stark et al. (2013). Hence, it is observed that both subjectively measured (e.g. selfreported perception) and objectively measured (e.g. Geographical Information System) environmental characteristics data can produce similar results when predicting health outcomes.

The Ecological System Theory founded by Bronfenbrenner (1979), which speculated the effects of the surrounding environment on a person's behaviour, provides a foundation for this study. Apart from having the ability to explain health outcomes, such as BMI, the environment is also highly influential on health behaviours. As such, it can be said that environment dictates energy consumption, energy expenditure and the health outcomes of a person.
It was noticed that DQ had a higher effect on BMI than PA. As such, this study supports Key Message 3 in the Malaysian Dietary Guidelines 2010, which urges Malaysians to "be physically active everyday" to encourage more people to utilise physical activity as a way to be healthier. Apart from that, the negative relationships between DQ and PA with BMI supports claims of previous studies that people who lead sedentary lifestyles and unhealthy eating habits were often found to have higher BMI.

As most of our neighbourhoods have no proper "walking and cycling facilities" as defined in the NEWS questionnaire, it was no surprise that the measurement model dropped the construct for measurement of PNBE as it does not fit to the local data set. The same was also true for the "food store type availability" construct under PNFE.

As exemplified by this study, specifically with the evidence of significance between the relationships of the food environment, built environment, diet quality, physical 
activity and BMI, humans share a complex yet intimate relationship with the environment as it influences behaviours and nurtures habits. As such, urban planning management decisions can have an influence on inhabitants, including health outcomes. Decisions made by federal, municipal and local authorities on urban planning agendas, as well as approval of land-use distribution, development plans and placement of activities in certain areas have long-term effects on its inhabitants (Kent \& Thompson, 2012). Thompson and McCue (2016) supported the idea that planning for healthy living is an inter-sectoral collaboration effort. When addressing health issues, including physical inactivity and obesity, one cannot deny the fact that partnerships between health professionals and planners (Thompson, 2007) in Malaysia will have an advantage.

Food environment characteristics that need to be prioritised and improved are to ease of access to and low selection of healthy food, such as low-fat products, meat and seafood within neighbourhood areas. A viable solution is establishing something similar to the farmer's market as practised in the U.S. and across Europe, bringing nutritious and fresh food to neighbourhoods that is lower in socioeconomic status, while increasing the selection of healthy food in the community.

In Malaysia, such activities (the selling of fresh fruits, vegetables, meat and seafood) can be observed at the local morning wet markets and pasar tani across neighbourhoods, or even some pasar malam. These local fresh outlets can be improved through incentives for more farmer participation and strategic placement of markets across neighbourhoods. The local authorities can also use this platform to spread awareness of healthy eating and urban farming through mobile educational programmes. Even supermarkets offer a selection of healthy products, but accessibility may be limited to the upper socio-economic section of society.

On the other hand, the characteristics of built environment that need attention are the provision of shade and presence of natural attractions on streets, to encourage walkability. Next, Khasef (2011) found that the traditional residential layout plans of having more alternate routes to go home increase the walkability of neighbourhoods. Furthermore, for areas with many cul-de-sacs, there should be connecting walkways so pedestrian is still able to get to their desired destinations via non-motorised vehicles (Lamíquiz \& López-Domínguez, 2015). The design of routes for motorised vehicles within neighbourhoods can also minimise nonresidents' mobility, so as to reduce the number of suspicious vehicles and also control the air pollution caused by traffic within the area.

Strategic placement of desired destinations can create a sense of presence to improve inhabitants' perceptions of their neighbourhood environments, which then encourages better diet quality and increases physical activity level, as well as achieving a normal BMI. It is important for healthy food stores, for example, to have a presence by being strategically placed within neighbourhoods where inhabitants feel closer to, rather than have a high density of healthy food stores within a neighbourhood, which are either not within close proximity to residential areas, or that it was not strategically placed to enhance visibility. As such, a neighbourhood can have a low density of healthy food stores. However, if the placement of such activity is calculated and planned, it could still deliver good results on increasing inhabitants' health.

From the above discussion, it highlights the importance of gauging the opinions and perceptions of inhabitants when drawing up context-specific improvement plans and programmes. The usage of self-reported perceptions in this study to understand the environmental characteristics that matters to the prediction of a person's BMI showed that social participation and inclusion should be an essential part in achieving spatial liveability. Understanding the root of problem from the inhabitants of the neighbourhood, which urban planners aim to plan for, is not only costeffective, but also saves time and are largely more successful than using the trial-and-error 
method to remedy problems such as healthrelated issues (Adams \& Tiesdell, 2012). Areaspecific inhabitants can tell urban planners and decision-makers on where improvements can be made and should be made, hence, facilitates in the reimagining and reinvention of spaces, while strengthening the people-place connection in the process. As mentioned by Adams and Tiesdell (2012), this is one of the main keys to improve inhabitants' quality of life.

\section{Limitations}

As the obesity phenomenon is a complex association between human behaviour and their environments, the following study limitations could not be avoided. Firstly, the study did not collect data of where the respondents procure their food. This is because it was thought to be a "consumer" factor of food environment data at an individual level, which was outside the scope of the study. Hence, for instance, even though there is a high presence of unhealthy food stores within close proximity to where the respondents live, the study is unsure if they do procure and consume the food from those stores. As pointed out by Hillier et al. (2013), there are people who are willing to travel outside their neighbourhoods to access and consume healthy food. Consequently, the source of their diet quality is unknown in this study.

The same goes to the exertion of physical activity in the study. Although the study does know how much and when the respondents carry out physical activities, i.e. during work, or travelling to destinations, or during leisure time; the study do not question where do they do these activities. physical activities during leisure time, for example, can be done at the park in their own area or at the neighbouring park, or at a gym. If most leisure time physical activities are done at gyms instead of outdoor parks, for example, it defeats the purpose of focusing on neighbourhood recreational park enhancements. As the study did not collect data on this aspect, it is highly recommended for future studies to include it when explaining BMI through environmental and behavioural studies.
Secondly, the study generalises the categories of "food store type" based on previous studies done in Western countries, whereby supermarkets and grocery stores were deemed as healthy food stores, while convenience stores and fast food restaurants were ascertained as unhealthy food stores. As mentioned earlier, when doing assessment, it is recommended to use a local data set to better reflect the situation of the study area. In conjunction to that, it is observed that there is an increase of food environment studies that specifically examine instore observations, such as the study conducted by Rose et al. (2009), which better identify what those stores offer or sell, and thus can determine the level of "healthiness" for the food store type in question, specifically for the study area.

This is particularly true as Kelly et al. (2014) highlighted that in the case of Thailand, which is a neighbouring country of Malaysia, people who make frequent visits to supermarkets and convenience stores were found to consume more unhealthy food, such as snacks, instant pre-packaged food and soft drinks, resulting in poorer diet quality. It is to note that in Southeast Asia, wet markets are more prevalent than in other regions. And the majority of items sold in those wet markets are fresh and raw food produce. Hence, in the circumstance of Malaysia, supermarket chains might not be as healthy as it seems when compared with local wet markets, which brings to the idea that perhaps supermarkets and wet markets should be examined separately in future studies.

Apart from that, the study was also unable to pin point if non-fast food restaurants in Malaysia can be categorised as a healthy or unhealthy food provider. This is because, for example, a non-fast food restaurant or stall in Malaysia could be offering an all-fried food menu, such as fried banana fritters, which are very high in fat and calories. As such, it is recommended for future studies to explore the area of in-store survey as part of the food environment aspect as it is important for diet quality influence. 


\section{Conclusion}

By estimating the food and built environment simultaneously, at least a small part of the cause of the obesity epidemic in Malaysia can now be explained. Not only did this study has identified the environmental characteristics that are significant in influencing a person's BMI through gauging self-reported perceptions, but it has also detected areas that needs to be improved. The findings of this study pointed out that the food and built environments in Malaysia at the moment are facilitating the obesity phenomenon. Moreover, with significant correlations found between the food and built environments, this denotes that both environments need to be planned concurrently so that it complements each other in creating a healthier spatial area.

The causal model produced in this study can be incorporated into a larger-scale model linking environmental characteristics to health behaviours and health outcomes. It provides a foundation that can be further enhanced, elaborated or modified to suit the assessment of other environmental settings, such as school or workplace environments. Apart from that, as pointed out by Thompson (2007), the environmental causal model is able to aid in future identification of potential health impacts (specifically diet quality, physical activity and BMI for the context of this study) before the approval of development plans. As such, an environmental health-related causal model, such as the one produced by this study, can be used to improve or influence future planning policies in an effort to create healthier living spaces.

\section{Acknowledgements}

The authors hereby gratefully acknowledge the assistance of Universiti Teknologi Malaysia and the Ministry of Education under the Fundamental Research Grant Scheme (FRGS No. FRGS/1/2018/SSI11/UTM/02/1) in funding the research.

\section{References}

Adams, D., \& Tiesdell, S. (2012). Shaping places: Urban planning, design and development. Routledge.

Agrawal, P., Gupta, K., Mishra, V., \& Agrawal, S. (2013). Effects of sedentary lifestyle and dietary habits on body mass index change among adult women in India: Findings from a follow-up study. Ecology of Food and Nutrition, 52(5), 387-406.

Asma', A., Nawalyah, A. G., Rokiah, M. Y., \& Mohd Nasir, M. T. (2011). Assessment of diet quality among married couples in a selected urban area in Selangor. Journal of Community Health, 16(2).

Blitstein, J. L., Snider, J., \& Evans, W. D. (2012). Perceptions of the food shopping environment are associated with greater consumption of fruits and vegetables. Public Health Nutrition, 15(6), 1124-1129.

Blunch, N. (2008). Introduction to structural equation modelling using SPSS and AMOS. Sage.

Bourdeaudhuij, I. D., Dyck, V., Salvo, D., Davey, R., Reis, R. S., Schofield, G., Sarmeinto, O. L., Mitas, J., Christiansen, L. B., McFarlane, D., Sugiyama, T., Ontoso, I.A., Owen, N., Conway, T. L., Sallis, J. F., \& Cerin, E. (2015). International study of perceived neighbourhood environmental attributes and Body Mass Index: IPEN Adult study in 12 countries. International Journal of Behavioral Nutrition and Physical Activity, 12(62).

Brickz Research Sdn. Bhd. (2019). https://www. brickz.my/

Bridle-Fitzpatrick, S. (2015). Food deserts or food swamps?: A mixed-methods study of local food environments in a Mexican city. Social Science and Medicine, 142, 202-213.

Bronfenbrenner, U. (1992). Ecological systems theory. Jessica Kingsley Publishers.

Casey, A. A., Elliott, M., Glanz, K., HaireJoshu, D., Lovegreen, S. L., Saelens, B. E., ... \& Brownson, R. C. (2008). Impact of 
the food environment and physical activity environment on behaviors and weight status in rural US communities. Preventive Medicine, 47(6), 600-604.

Caspi, C. E., Sorensen, G., Subramaniam, S. V., \& Kawachi, I. (2012). The local food environment and diet: A systematic review. Health and Place, 18(5), 1172-1187.

Cheong, S. M., Jasvinder, K., Lim, K. H., Ho, B. K., \& Mohmad, S. (2013). Use and understanding of nutrition labelling among elderly men and women in Malaysia. Mal $J$ Nutr, 19(3), 353-362.

Claudel, S. E., Shiroma, E. J., Harris, T. B., Mode, N. A., Ahuja, C., Zonderman, A. B., Evans, M. K., \& Willey, T. M. P. (2019). Cross-sectional associations of neighborhood perception, physical activity, and sedentary time in community-dwelling, socioeconomically diverse adults. Frontiers in Public Health, 7.

Cummins, S., Curtis, S., Diez-Roux, A. V., \& Macintyre, S. (2007). Understanding and representing 'place' in health research: a relational approach. Social Science \& Medicine, 65(9), 1825-1838.

Dannenberg, A. L., Jackson, R. J., Frumkin, H., Schieber, R. A., Pratt, M., Kochtitzky, C., \& Tilson, H. H. (2003). The impact of community design and land-use choices on public health: A scientific research agenda. Am J Public Health, 93(9), 1500-1508.

Duncan, M. J., Birch, S., Woodfield, L., \& Nakeeb, Y. A. (2012). Perceptions of the built environment in relation to physical activity and weight status in British adolescents from Central England. International Scholarly Research Network, 2012.

Department of Chronic Diseases and Health Promotion/Surveillance and PopulationBased Prevention/World Health Organization. Retrieved on December 28, 2017 from http://www.who.int/ncds/ surveillance/steps/GPAQ/en/.
Feng, J., Glass, T. A., Curriero, F. C., Stewart, W. F., \& Schwartz, B. S. (2010). The built environment and obesity: A systematic review of the epidemiology. Health \& Place, 16(2), 175-190

Fokeena, W. B., Jamaluddin, R., \& Khaza'ai, H. (2016). Development and assessment of the reliability and validity of a diet quality index in a sample of Malaysian university students. Journal of Food and Nutrition Research, 4(4), 251-257.

Glanz, K., Sallis, J. F., Saelens, B. E., \& Frank, L. D. (2005). Healthy nutrition environments: Concepts and measures. American Journal of Health Promotion, 19(5), 330-333.

Gibson, D. M. (2011). The neighbourhood food environment and adult weight status: Estimates from longitudinal data. American Journal of Public Health, 101(1), 71-78.

Green, S. H., \& Glanz, K. (2015). Development of the perceived nutrition environment measures survey. Am J Prev Med, 49(1), 50-61.

Gutierrez, T. B., Moore, K. A. B., Auchincloss, A. H., Mojahid, M. S., August, C., Sanchez, B. N., \& Roux, A. V. D. (2017). Neighborhood physical environment and changes in Body Mass Index: Results from the multi-ethnic study of Atherosclerosis. American Journal of Epidemiology, 186(11).

Hair, J., Black, W., Babin, B., \& Anderson, R. (2010). Multivariate data analysis (7th ed.). Upper Saddle River, NJ, USA: PrenticeHall, Inc.

Hamid Jan, J. M., Amal, K. M., Hasmiza, H., Pim, C. D., Ng, L. O., \& Wan Manan, W. M. (2011). Effect of gender and nutritional status on academic achievement and cognitive function among primary school children in a rural district in Malaysia. Mal J Nutr, 17(2), 189-200.

Hanibuchi, T., Nakaya, T., Yonejima, M., \& Honjo, K. (2015). Perceived and objective measures of neighbourhood walkability and physical activity among adults in 
Japan: A multilevel analysis of a nationally representative sample. Int $J$ Environ Res Public Health, 12(10), 13350-13364.

Hayati Adilin, M. A. M., Holdsworth, M., McCullough, I., Swift, J. A., \& Norimah, A. K. (2015). Wholeschool mapping to investigate the school's environment's potential to promote a healthy diet and physical activity in Malaysia. Mal J Nutr, 21(1), 1-14.

Hillier, A., Cannuscio, C. C., Karpyn, A., McLaughlin, J., Chilton, M., \& Glanz, K. (2013). How far do low-income parents travel to shop for food? Empirical evidence from two urban neighbourhoods. Urban Geography, 32(5), 712-729.

Hu, L. T., \& Bentler, P. M. (1999). Cutoff criteria for fit indexes in covariance structure analysis: Conventional criteria versus new alternatives. Structural Equation Modeling: A Multidisciplinary Journal, 6(1), 1-55.

Inglis, V., Ball, K., \& Crawford, D. (2008). Socioeconomic variations in women's diets: What is the role of perceptions of the local food environment? Journal of Epidemiology and Community Health, 62(3), 191-197.

Institute for Public Health (IPH). (2015). National Health and Morbidity Survey 2015 (NHMS 2015). Vol. II: Non-communicable diseases, risk factors and other health problems. Kuala Lumpur: Ministry of Health Malaysia.

Kashef M. (2011). Walkability and residential suburbs: A multidisciplinary perspective. Journal of Urbanism International Research on Placemaking and Urban Sustainability, 4(1), 39-56.

Kearns, R., \& Moon, G. (2002). From medical to health geography: novelty, place and theory after a decade of change. Progress in Human Geography, 26(5), 605-625.

Kell, K. P., Judd, S. E., Pearson, K. E., Shikany, J. M., \& Fernández, J. R. (2015). Associations between socio-economic status and dietary patterns in US black and white adults. The British Journal of Nutrition, 113(11), 1792 1799.

Kelly, M., Seubsman, S., Banwell, C., Dixon, J., \& Sleigh, A. (2014). Thailand's food retail transition: Supermarket and fresh market effects on diet quality and health. British Food Journal, 116(7), 1180-1193.

Kent, J., \& Thompson, S. (2012). Health and the built environment: Exploring foundations for a new interdisciplinary profession. Journal of Environmental and Public Health.

Lamíquiz, P. J., \& López-Domínguez, J. (2015). Effects of built environment on walking at the neighbourhood scale. A new role for street networks by modelling their configurational accessibility? Transportation Research Part A, 74(2015), 148-163.

Landis, R. S. (2005). Standardized regression coefficients. Encyclopedia of statistics in behavioral science. Chicester: John Wiley \& Sons Ltd.

Lee, P. Y., Cheah, W. L., Chang, C. T., \& Siti Raudzah, G. (2012). Childhood obesity, self-esteem and health-related quality of life among urban primary schools children in Kuching Sarawak, Malaysia. Mal J Nutr, 18(2), 207-219.

Martin, K. R., Shreffler, J., Schoster, B., \& Callahan, L. F. (2011). Associations of perceived neighbourhood environments on health status outcomes in persons with Athritis. Athritis Care Res (Hoboken), 62(11), 1602-1611.

Mesas, A. E., Guallar-Castillón, P., LeónMunoz, L. M., Graciani, A., Lopez-Garcia, E., Gutiérrez-Fisac, J. L., ... \& RodriguezArtalejo, F. (2012). Obesity-related eating behaviors are associated with low physical activity and poor diet quality in Spain. The Journal of Nutrition, 142(7), 1321-1328.

Ministry of Health Malaysia, National Coordinating Committee on Food and 
Nutrition. (2010). Malaysian Dietary Guidelines 2010. Putrajaya: Ministry of Health Malaysia, Nutrition Division.

Ministry of Housing and Local Government Malaysia, Town and Country Planning Department of Peninsular Malaysia. (2013). Planning Standards and Guidelines Manual Johor. Johor: State Planning Committee.

Morland, K., Roux, A. V. D., \& Wing, S. (2006). Supermarkets, other food stores, and obesity: The atherosclerosis risk in communities study. American Journal of Preventive Medicine, 30(4), 333-339.

Norhasmah, S., Zalilah, M. S., Mohd Nasir, M. T., Kandiah, M., \& Asnarulkhadi, A. S. (2010). A qualitative study on coping strategies among women from food insecurity households in Selangor and Negeri Sembilan. Mal J Nutr, 16(1), 39-54.

NSP-NCD 2010. National Strategic Plan for Non-Communicable Diseases (NSPNCD): Mid Term Strategic Plan to Further Strengthen the Cardiovascular Diseases and Diabetes Prevention and Control Program in Malaysia (2010-2014). NonCommunicable Disease Section, Disease Control Division, Ministry of Health Malaysia.

Nurliyana, A. R., Mohd Nasir, M. T., Zalilah, M. S., \& Rohani, A. (2015). Dietary patterns and cognitive ability among 12 to 13 yearold adolescents in Selangor, Malaysia. Public Health Nutr, 18(2), 303-12.

Ooi, S. Y., Mohd Nasir, M. T., Barakun Nisak, M. Y., \& Chin, Y. S. (2015). Validation of a food choice questionnaire among adolescents in Penang, Malaysia. Mal $J$ Nutr, 21(1), 25-35.

Ploeg, M. V. (2010). Access to affordable, nutritious food is limited in "food deserts". Amber Waves, 8(1), 20-27.

Poh, B. K., Kathryn Tham, B. L., Wong, S. N., Winnie Chee, S. S., \& Tee, E. S. (2012). Nutritional status, dietary intake patterns and nutrition knowledge of children 5-6 years attending kindergartens in the Klang Valley, Malaysia. Mal J Nutr, 18(2), 231242.

Putrik, P., Amelsvoort, L. V., Vries, N. K., Mujakovic, S., Kunst, A. E., Oers, H. V., Jansen, M., \& Kant, I. J. (2015). Neighborhood environment is associated with overweight and obesity, particularly in older residents: Results from cross-sectional study in Dutch Municipality. Journal of Urban Health: Bulletin of the New York Academy of Medicine, 92(6), 1038-1051

Raja, S., Li, Y., Roemmich, J., Ma, C., Epstien, L., Yadav, P., \& Ticoalu, A. B. (2010). Food environment, built environment, and women's BMI: Evidence from Erie County, New York. Journal of Planning Education and Research, 29(4), 444-460.

Ranasinghe, C., Gamage, P., Katulanda, P., Andraweera, N., Thilakarathne, S., \& Tharanga, P. (2013). Relationship between body mass index (BMI) and body fat percentage, estimated by bioelectrical impedance, in a group of Sri Lankan adults: A cross sectional study. BMC Public Health, 13(1), 1-8.

Rezali, F. W., Chin, Y. S., Mohd Shariff, Z., Mohd Yusof, B. N., Sanker, K., \& Woon, F. C. (2015). Evaluation of diet quality and its associated factors among adolescents in Kuala Lumpur, Malaysia. Nutr Res Pract, 9(5), 511-516.

Romieu, I., Dossus, L., Barquera, S., Blottière, H. M., Franks, P. W., Gunter, M., ... \& Nishida, C. (2017). Energy balance and obesity: What are the main drivers? Cancer Causes and Control, 28(3), 247-258.

Rose, D., Hutchinson, P. L., Bodor, J. N., Swalm, C. M., Farley, T. A., Cohen, D. A., \& Rice, J. C. (2009). Neighbourhood food environments and body mass index: the importance of in-store contents. American Journal of Preventive Medicine, 37(3), 214219. 
Rummo, P. E., Meyer, K. A., Boone-Heinonen, J., Jacobs Jr., D. R., Kiefe, C. I., Lewis, C. E., Steffen, L. M., \& Gordon-Larsen, P. (2015). Neighbourhood availability of convenience stores and diet quality: Findings from 20 years of follow-up in the coronary artery risk development in young adults study. American Journal of Public Health, 105(5), e65-e73.

Saelens, B. E., Sallis, J. F., Black, J. B., \& Chen, D. (2003). Neighbourhood-based differences in physical activity: An environment scale evaluation. American Journal of Public Health, 93(9), 1552-1558.

Sallis, J. F. (2009). Measuring physical activity environments: A brief history. American Journal of Preventive Medicine, 36(4), S86-S92.

Sallis, J. F., Floyd, M. F., Rodríguez, D. A., \& Saelens, B. E. (2012). Role of built environments in physical activity, obesity, and cardiovascular disease. Circulation, 125(5), 729-737.

Stark, J. H., Neckerman, K., Lovasi, G. S., Konty, K., Quinn, J., Arno, P., ... \& Rundle, A. (2013). Neighbourhood food environments and body mass index among New York City adults. J Epidemiol Community Health, 67(9), 736-742.

Suzana, S., Boon, P. C., Normah, C. D. (2013). Malnutrition risk and its association with appetite, functional and psychosocial status among elderly Malays in an agricultural settlement. Mal J Nutr, 19(1), 65-75.

Thompson, S. (2007). A planner's perspective on the health impacts of urban settings. New South Wales Public Health Bulletin, 18(10), 157-160.

Thompson, S., \& McCue, P. (2016). Healthy planning: An evolving collaborative partnership. Urban Policy and Research, 34(1), 73-89.

Townshend, T., \& Lake, A. (2017). Obesogenic environments: Current evidence of the built and food environments. Perspectives in Public Health, 137(1), 38-44.

Treuhaft, S., \& Karpyn, A. (2010). The grocery gap: Who has access to healthy food and why it matters. Policy Link.

Tucker, L. R., \& Lewis, C. (1973). A reliability coefficient for maximum likelihood factor analysis. Psychometrika, 38(1), 1-10.

Wan Nazaimoon, W. M., Aziz al-Safi, I., Amir, S., Ikram Shah, I., Kamarul Imran, M., Khalid, A. K., Nor Azmi, K., Nor Azwany, Y., Norlaila, M., Osman, A., Siti Hamida, \& Wan Mohamad, W. B. (2011). Prevalence of metabolic syndrome and its risk factors in adult Malaysians: Results of a nationwide survey. Diabetes Research and Clinical Practice, 96(1), 239-245.

Waxman, A. (2004). WHO global strategy on diet, physical activity and health. Food and Nutrition Bulletin, 25(3), 292-302.

Webb, T. L. G., Egnot, N. S., Nugroho, A., Dubowitz, T., \& Troxel, W. M. (2020). Changes in perceptions of neighbourhood environment and Cardio-metabolic outcomes in two predominantly African American neighborhoods. BMC Public Health, 20(52).

Wheaton, B., Muthen, B., Alwin, D. F., \& Summers, G. F. (1977). Assessing reliability and stability in panel models. Sociological Methodology, 8, 84-136.

Wiley, T. M. P., Ayers, C. R., Lemos, J. A., Lakoski, S. G., Vega, G. L., Grundy, S. Das, S. R., Richard, K. B., \& Albert, M. A. (2013). Relationship between perceptions about neighborhood environment and prevalent obesity: Data from the Dallas Heart Study. Obesity (Silver Spring), 21(1), 14-21.

Wolf, E. J., Harrington, K. M., Clark, S. L., \& Miller, M. W. (2013). Sample size requirements for structural equation models: An evaluation of power, bias and solution propriety. Educational and Psychological Measurement, 76(6), 913-934. 
Yu, R., Cheung, O., Lau, K., \& Woo, J. (2017). Associations between perceived neighbourhood walkability and walking time, wellbeing, and loneliness in community-dwelling older Chinese people in Hong Kong. International Journal of
Environmental Research and Public Health, 14, 1199-1124.

Zalina, A. Z., Lee, V. C., \& Kandiah, M. (2012). Relationship between nutritional status, physical activity and quality of life among gastrointestinal cancer survivors. Mal $\mathrm{J}$ Nutr, 18(2), 255-264. 